\title{
Rancangan Website Pembelajaran Terintegrasi dengan Modul Digital Fisika Menggunakan 3D PageFlip Professional
}

\author{
Fauzi Bakri $^{\text {a) }}$, Betty Zelda Siahaan ${ }^{\text {b) }}$, A. Handjoko Permana ${ }^{\text {c) }}$ \\ Program Studi Pendidikan Fisika, Universitas Negeri Jakarta Jl. Rawamangun Muka No.1, \\ Jakarta 13220

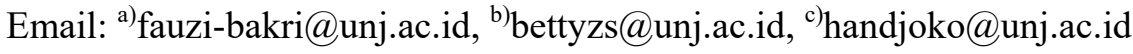

\begin{abstract}
This article is focused on learning website design techniques that are integrated with digital module physics using 3D PageFlip Professional. The digital module physics used a digital module research-based 3D PageFlip Professional development. To use more widely, will require online media as disseminating the use of these digital module. Online learning of course not only upload module files into the network. An integrated website is required to display this digital module online. Learning websites designed to require the installation of Adobe Flash on the browser to be accessible to users. Learning websites have been able to display video, animation, and instrument test integrated in 3D PageFlip Professional-based modules.
\end{abstract}

Keywords: Website of learning, digital modules, physics, 3D PageFlip Professional

\begin{abstract}
Abstrak
Artikel ini difokuskan pada teknik perancangan website pembelajaran yang terintegrasi dengan modul digital fisika menggunakan 3D PageFlip Professional. Modul digital fisika yang digunakan merupakan modul digital hasil penelitian pengembangan berbasis 3D PageFlip Professional. Untuk mendesiminasikannya secara lebih luas, tentu dibutuhkan media online sebagai sarana penyebarluasan penggunaan modul digital ini. Pembelajaran secara online tentu tidak hanya semata mengunggah file modul ke dalam jaringan. Diperlukan website yang terpadu untuk menampilkan modul digital ini secara online. Website pembelajaran yang dirancang memerlukan instalasi Adobe Flash pada browser agar dapat diakses pengguna. Website pembelajaran telah dapat menampilkan video, animasi, instrumen tes yang terintegrasi di dalam modul berbasis 3D PageFlip Professional.
\end{abstract}

Kata-kata kunci: Website pembelajaran, modul digital, Fisika, 3D PageFlip Professional

\section{PENDAHULUAN}

Pengembaangan bahan ajar berbasis TI (Teknologi Informasi) menjadi salah satu trend penelitian dalam dunia pendidikan, termasuk dalam bidang pembelajaran sains Fisika. Di pembelajaran Fisika sendiri, integrasi TI sudah menjadi kebutuhan, karena terbukti dapat membantu proses pembelajaran menjadi lebih efektif dan pada akhirnya dapat meningkatkan pemahaman siswa. Melalui bantuan TI, guru dapat menanamkan nilai-nilai terkait dengan mata pelajaran Fisika, seperti penelitian mengenai integrasi nilai-nilai Matematika, Sains, Teknologi, Bencana, dan Karakter (MSTBK) melalui materi Gerak Harmonis, Momentum, dan Impuls (Fitri 2015) yang terbukti berpengaruh nyata pada hasil 
belajar. Pada penelitian terkait e-learning dengan fitur tambahan, diketahui bahwa e-learning yang dilengkapi dengan virtual library merupakan bahan ajar yang berpotensi dapat meningkatkan keefektifan pelaksanaan praktikum Fisika Dasar (Agustine 2014).

Penelitian lainnya tentang pengembangan e-module sebagai bahan ajar Fisika SMA Kelas XI Kurikulum 2013 menunjukkan bahwa hasil uji validasi mencapai persentase sebesar 94,09\% menurut ahli materi, 93,64\% menurut ahli media, 82,79\% menurut ahli pembelajaran dan 95,23\% menurut guru fisika SMA. Hasil uji coba e-module fisika terhadap siswa menunjukkan persentase capaian sebesar 84,45\%. Dari penelitian ini disimpulkan bahwa e-module Fisika sesuai Kurikulum 2013 hasil pengembangan telah memenuhi persyaratan sebagai bahan ajar fisika SMA kelas XI (Ghaliyah 2015).

Penelitian mengenai pengembangan media pembelajaran Fisika Digital Book Bilingual dengan memanfaatkan Kvisoft Flipbook untuk peserta didik Kelas X Semester 1 Pokok Bahasan Hukum Newton menunjukkan hasil bahwa media pembelajaran Fisika berupa Buku Digital yang disusun sesuai dengan aturan penulisan modul pada materi Hukum Newton dan Aplikasinya untuk SMA/MA kelas X dari keseluruhan aspek memenuhi kriteria sangat baik oleh 27 peserta didik dari 30 peserta didik dan kriteria baik oleh 3 peserta didik dari 30 peserta didik. Penilaian kriteria tersebut berdasarkan angket yang disusun sesuai dengan karakteristik modul berkriteria baik menurut Kemdiknas tahun 2008 (Fauziyah 2013). Penelitian lain terkait buku digital berbasis multimedia menunjukkan bahwa buku digital ini dinilai layak dijadikan media pembelajaran dengan persentase rata-rata $85 \%$ dan berdasarkan angket uji lapangan persentase rata-rata 79,55\% (Nurtriyono 2012). Tindak lanjutnya telah dihasilkan modul digital fisika berbasis discovery learning yang memenuhi kriteria sangat baik dan layak digunakan sebagai bahan belajar mandiri untuk peserta didik SMA (Bakri 2016)

Arah pengembangan penelitian terkait bahan ajar digital meliputi segi desain pembelajaran (terlihat dari cara penyajian modul), kebahasaan, variasi software, dan kekuatan multimedia yang digunakan. Untuk memudahkan penyebaran modul elektronik untuk pembelajaran fisika, diperlukan fasilitas yang mudah dan efisien. Fasilitas yang mendukung adalah memanfaatkan laman (website). Artikel ini fokus membahas bagaimana menampilkan modul digital yang merupakan penggabungan unsur pengembangan dari segi desain pembelajaran dengan kekuatan multimedia dan fasilitas online agar dapat diakses secara tak terbatas ruang dan waktu. Modul digital yang terintegrasi dalam website ini juga dilengkapi dengan evaluasi secara online akhirnya menjadi suatu bagian pengembangan bahan pembelajaran yang disajikan secara digital.

\section{METODE}

Metode penelitian dan pengembangan untuk menghasilkan website pembelajaran ini menggunakan strategi pengembangan yang dikemukakan oleh Thiagarajan. Dalam merancang website ini, langkah-langkah pengembangan yang digunakan berbasis 4D dengan tahapan sebagai berikut: Define, Design, Develop, dan Dissemination (Thiagarajan 1974).

Tahapan I define, yaitu tahap penetapan dan pendefinisian syarat-syarat yang harus dipenuhi untuk produk yang akan dihasilkan. Ada lima langkah yang harus dilakukan, yaitu melakukan frontend analysis, learner analysis, task analysis, concept analysis dan specifying objectives. Lima langkah ini meliputi analisis awal meliputi referensi keefektifan media online, pengaruh pembelajaran berbasis TI, dilanjutkan dengan menganalisis karakter siswa sebagai pengguna, indikator pembelajaran, dan strategi tampilan media yang dihasilkan. Adapun media modul yang dihasilkan sudah mengintegrasikan komponen-komponen pembelajaran yang meliputi: teks, gambar, gambar cover, video, animasi, tes formatif, soal evaluasi, serta game grafis. Adapun software yang digunakan yaitu: Microsoft Office Word, Adobe Photoshop CC, Adobe Premiere Pro \& Adobe Media Encoder, iSpring Suite 8, iSpring QuizMaker, Graph Game, dan 3D PageFlip Professional.

Tahap II design, pada tahap ini dilakukan perancangan modul online berbasis 3D PageFlip Professional. Ada empat langkah yang dilakukan dalam perancangan tampilan modul online berbasis 3D PageFlip Professional, yaitu constructing criterion-referenced test, media selection, format selection dan initial design. Langkah ini meliputi kajian tentang standar kualitas media yang akan dihasilkan, pemilihan media yang sesuai dengan kebutuhan, pemilihan format tampilan yang dipilih 
sesuai dengan tujuan yang ditetapkan dan melakukan perancangan awal media modul online berbasis 3D PageFlip Professional.

Tahap III develop, yang meliputi pengembangan perangkat modul berbasis 3D PageFlip Professional yang ditampilkan dalam bentuk website pembelajaran. Pada tahap ini dilakukan penilaian keberfungsian semua komponen yang dipasangkan sesuai dengan tujuan yang sudah ditetapkan. Bentuk modul ini menintegrasikan tampilan dalam bentuk Microsoft Office Word, Adobe Photoshop CC, Adobe Premiere Pro \& Adobe Media Encoder, iSpring Suite 8, iSpring QuizMaker, Graph Game yang terintegrasi dalam software 3D PageFlip Professional. Pada tahap ini juga dilakukan uji kelayakan dari tampilan modul berbasis $3 D$ PageFlip Professional yang ditampilkan dalam website pembelajaran.

Tahap IV disseminate, yaitu tahap mempromosikan produk hasil pengembangan agar dapat diterima oleh penggunanya. Modul yang dihasilkan ini diperkenalkan kepada pengguna, yaitu siswa SMA. Proses ini untuk mendapat tanggapan dari pengguna untuk penyempurnaan tampilan agar lebih efektif, dan efisien dalam menunjang pembelajaran.

\section{HASIL DAN PEMBAHASAN}

Sesuai dengan langkah penelitian dengan strategi 4D, telah dihasilkan bentuk website pembelajaran untuk menyebarluaskan modul pembelajaran fisika berbasis $3 D$ PageFlip Professional. Untuk menghasilkan website yang dapat menampilkan modul digital fisika berbasis $3 D$ PageFlip Professional secara online, diperlukan langkah-langkah sebagai berikut.

\section{Menyiapkan Hosting}

Dalam hal ini, peneliti menggunakan hosting dengan kapasitas unlimited. Tujuannya adalah agar tidak terjadi pembatasan ruang untuk penyimpanan data secara online, mengingat fitur-fitur yang terdapat dalam modul digital terdiri dari teks, gambar, video, animasi, simulasi flash dengan ukuran file yang besar. GAMBAR 1 menunjukkan screenshot spesifikasi hosting yang digunakan. Disk Space hosting yang digunakan dengan kapasitas unlimited sehingga saat proses unggah, tidak akan menjadi masalah terutama saat file yang akan diunggah berukuran besar.

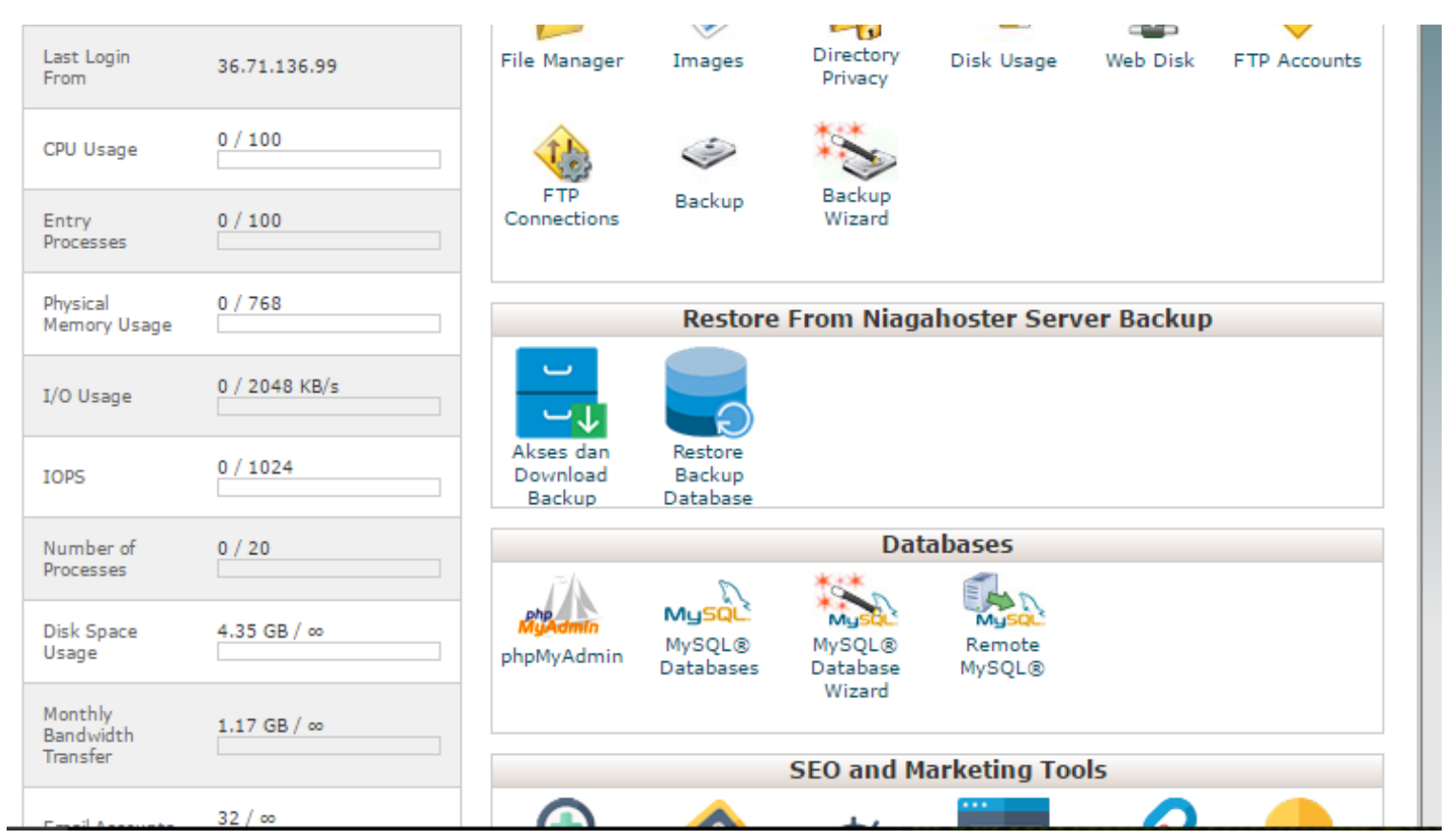

GAMBAR 1. Screenshot spesifikasi hosting yang digunakan. 


\section{Menyiapkan Domain}

Domain yang digunakan dalam rancangan ini adalah http://md1.fisika-unj.ac.id.

\section{Publish Modul Digital dalam Bentuk HTML}

Modul Digital yang akan diunggah secara daring, harus dipublish dalam bentuk html, seperti yang ditunjukkan GAMBAR 2.

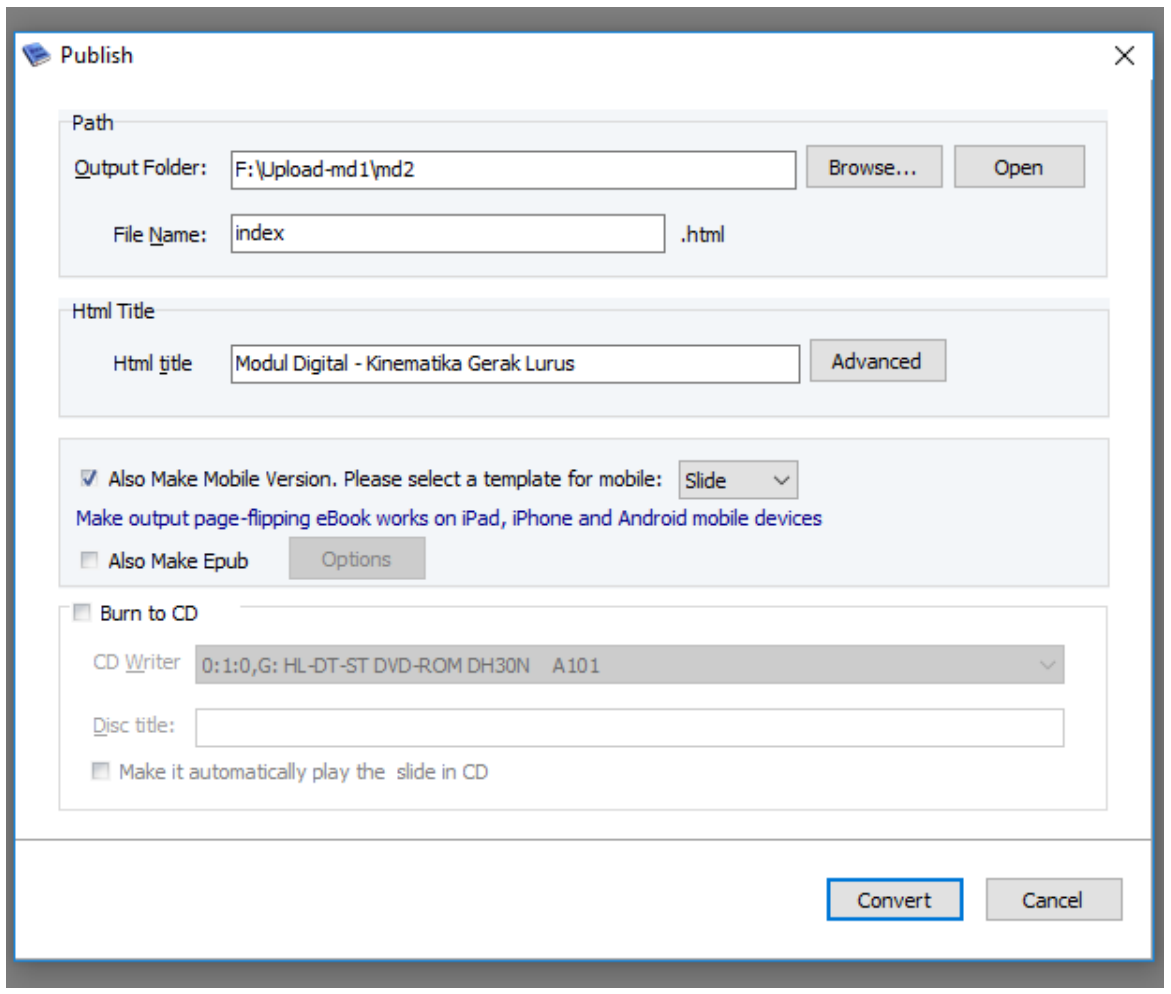

GAMBAR 2. Publish Modul Digital ke bentuk html.

\section{Upload Output File ke Server}

Setelah proses publish (convert) selesai, akan dihasilkan beberapa output seperti pada GAMBAR 3. Output yang dihasilkan berupa folder files dan mobile, dan file html. Folder files berisi semua unsur pembangun modul, folder mobile sama dengan folder files, jika modul diakses melalui browser handphone, sedangkan file html berisi script perintah menampilkan modul dalam bahasa html.

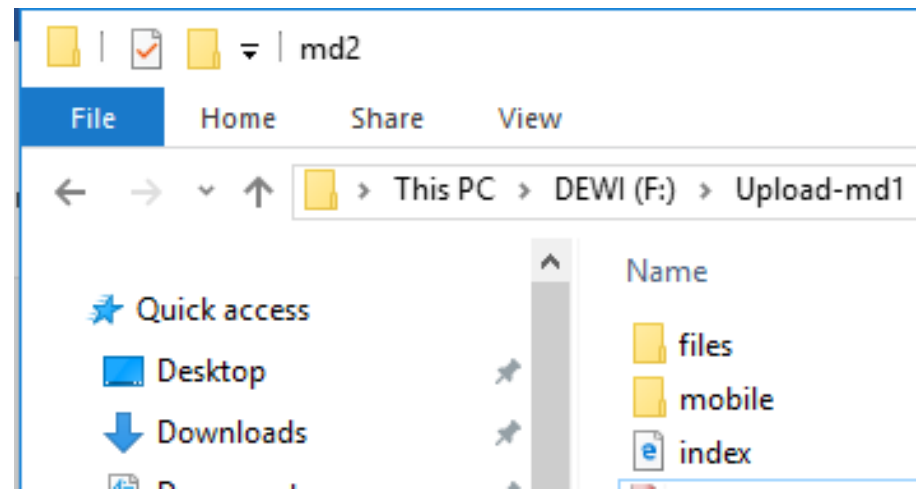

GAMBAR 3. Output yang dihasilkan setelah selesai Publish dalam bentuk HTML. 
Selanjutnya, output tersebut diunggah ke dalam server hosting, seperti ditunjukkan GAMBAR 4

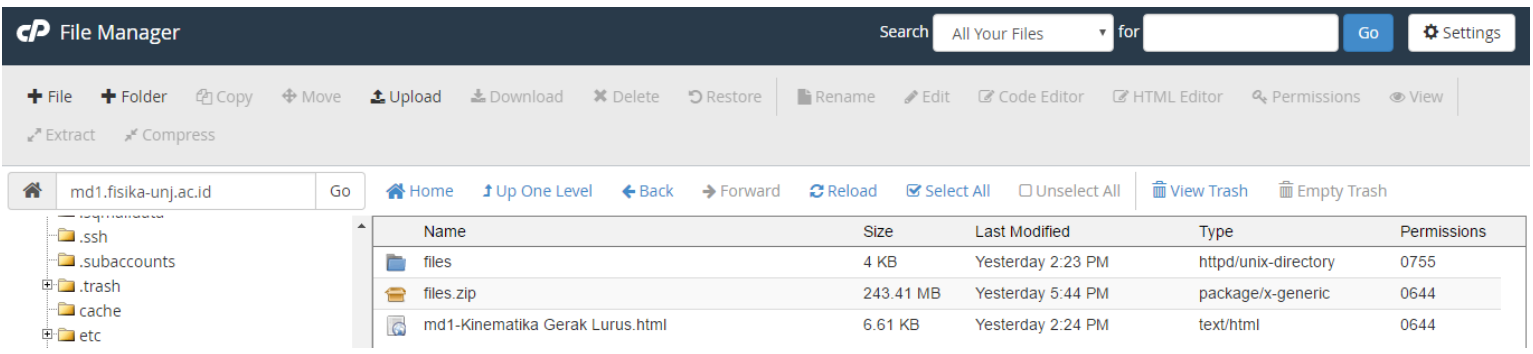

GAMBAR 4. Output yang berhasil diunggah ke server.

\section{Ujicoba Alamat Website Secara Online}

Selanjutnya, dilakukan ujicoba, dan modul digital berhasil diakses secara online, seperti ditunjukkan GAMBAR 5. Adapun alamat aksesnya adalah:

http://md1.fisika-unj.ac.id/md1-Kinematika\%20Gerak\%20Lurus.html.

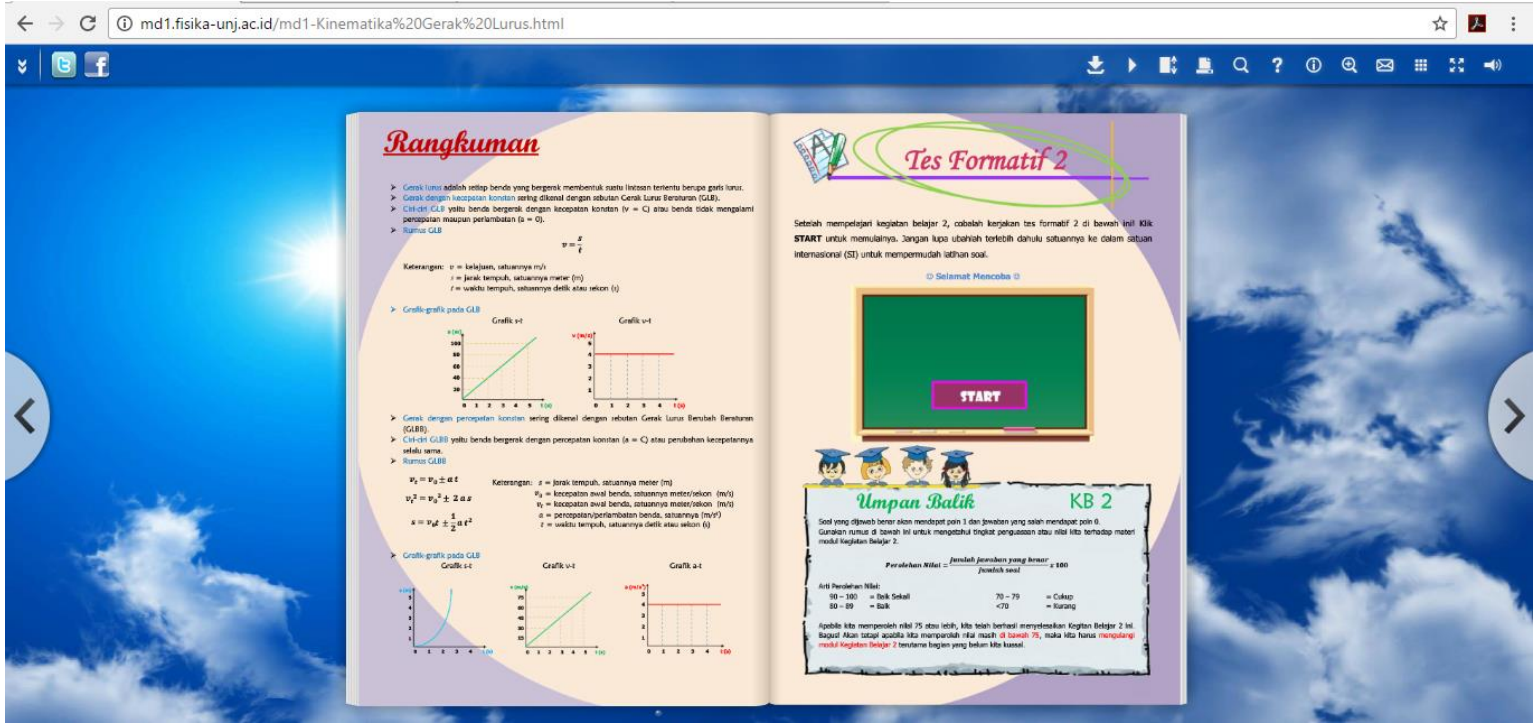

GAMBAR 5. Modul Digital Diakses secara online dengan alamat http://md1.fisika-unj.ac.id/md1-Kinematika\%20Gerak\%20Lurus.html.

Ujicoba website modul digital ini juga dilakukan pada berbagai browser. Diketahui bahwa browser yang tidak mendukung Adobe Flash Player tidak dapat menampilkan website modul digital. Versi yang dipersyaratkan adalah Adobe Flash Player 10.0.0 atau lebih tinggi seperti yang ditunjukkan GAMBAR 6 berikut.

\section{$\leftarrow \rightarrow \circlearrowright \quad$ md1.fisika-unj.ac.id/md1-Kinematika\%20Gerak\%20Lurus.html}

To view this page ensure that Adobe Flash Player version 10.0.0 or greater is installed.

Get ADOBE

FLASH* PLAYER

GAMBAR 6. Tampilan browser yang tidak dapat akses modul digital karena tidak mendukung Flash Player. 


\section{SIMPULAN}

Modul fisika berbasis 3D PageFlip Professional dapat ditampilkan dalam bentuk online dalam laman (website) pembelajaran. Setelah dilakukan modifikasi beberapa bagian modul, semua komponen modul fisika berbasis 3D PageFlip Professional dapat berfungsi dengan baik setelah ditampilkan berbasis website pembelajaran.

\section{UCAPAN TERIMAKASIH}

Penulis mengucapkan terimakasih kepada Direktorat Riset dan Pengabdian Masyarakat, Direktorat Jenderal Penguatan Riset dan Pengembangan, Kementerian Riset, Teknologi, dan Pendidikan Tinggi atas dana penelitian sesuai dengan Surat Perjanjian Pelaksanaan Penugasan Penelitian Hibah Bersaing Nomor: 03/SP2H/DRPM/LP-UNJ/HB/III/2016 Tanggal 22 Maret 2016.

\section{REFERENSI}

Agustine, D., Wiyono, K., dan Muslim, M. Pengembangan E-Learning Berbantuan Virtual Laboratory untuk Mata Kuliah Praktikum Fisika Dasar II di Program Studi Pendidikan Fisika FKIP UNSRI. Jurnal Inovasi dan Pembelajaran Fisika Vol.1 No.1, Mei 2014 ISSN: 2355-7109.

Bakri F., Handjoko Permana A., dan Siahaan B. Z. Pengembangan Modul Digital Fisika Berbasis Discovery Learning pada Pembelajaran Fisika SMA, Proseding Seminar Nasional Fisika dan Aplikasinya, 19 Nopember 2016, 227-235

Fauziyah, A. N. 2013. Pengembangan Media Pembelajaran Fisika Digital Book Bilingual dengan Memanfaatkan Kvisoft Flipbook untuk Peserta Didik Kelas X Semester 1 Pokok Bahasan Hukum Newton, Skripsi Universitas Sebelas Maret, Surakarta.

Fitri, A., Asrizal, dan Amir, H. Pengaruh Bahan Ajar ICT Mengintegrasikan MSTBK Materi Gerak Harmonis, Momentum, dan Impuls terhadap Kompetensi Fisika Siswa Kelas XI SMAN 1 Lubuk Alung. Pillar of Physics Education, Vol. 5. April 2015, 89-96.

Ghaliyah, Siti, Fauzi Bakri, Siswoyo, Pengembangan Modul Elektronik Berbasis Model Learning Cycle 7E pada Pokok Bahasan Fluida Dinamik untuk Siswa SMA Kelas XI, Prosiding Seminar Nasional Fisika (E-Journal) SNF 2015, Vol IV, Oktober 2015, 149-154

Nurtriyono. 2012. Pengembangan Buku Digital Berbasis Multimedia Sebagai Media Pembelajaran Fisika Tingkat SMA, Skripsi Universitas Negeri Jakarta, Jakarta.

Thiagarajan S., D.S. Semmel, M.I. Semmel, 1974, Instructional Development for Training Teachers of Esceptional Cildren: A Sourebook, Center for Innovation in Teaching the Handicapped, Indiana USA. 